\title{
Maturity dependence of quality, quantity and chemical constituents of bark and leaf oil of Ceylon Cinnamon (Cinnamomum zeylanicum Blume)
}

\author{
A.A. Wijeweera ${ }^{1}$, J.W. Hewage ${ }^{2 *}$, G.G. Jayasinghe ${ }^{1}$, S. H. Wadumethrige ${ }^{2}$, S.R. Hettiarachchi ${ }^{3}$ \\ and K.G.G. Wijesinghe ${ }^{1}$ \\ ${ }^{I}$ National Cinnamon Research and Training Center, Department of Export Agriculture, Sri Lanka \\ ${ }^{2}$ Department of Chemistry, University of Ruhuna, Matara, Sri Lanka \\ ${ }^{3}$ Department of Chemistry, The Open University of Sri Lanka
}

Correspondence: jinasena@chem.ruh.ac.lk; (iD https://orcid.org/0000-0001-7713-7484

Received: $2^{\text {th }}$ November 2019, Revised: $17^{\text {th }}$ March 2020, Accepted: $29^{\text {th }}$ May 2020

\begin{abstract}
The maturity dependence of quality and quantity of bark and leaf oils of Ceylon Cinnamon were studied. Both genetic factors and ecological factors were maintained constant using two accessions of Ceylon Cinnamon, Sri Gamunu and Sri Vijaya, vegetatively cultivated at a field in the same agroecological zone, IL1a $\left(6^{0} 1.7820 N^{\prime} ; \quad 80^{0} 33.4990^{\prime} \mathrm{E} ; 22.3\right.$ amsl.). Three maturity stages of plants, more than 5 years, between 2-2.5 years, and between 1.5-2 years, were used. Morphological analysis in two varieties showed that stick weight, bark dry weight, and leaf dry weight per stick were not significantly different in two varieties at the significance level $\alpha=0.05$. When compared the oil contents, Sri Gamunu had a higher oil yield than Sri Vijaya and both showed significantly higher yield at maturity stage of 2-2.5 years which was about the customarily identified maturity for harvesting $(\sim 2$ years). In Sri Gamunu, about $78 \%$ of bark oil consists of cinnamaldehyde and cinnamyl acetate while those in Sri Vijaya accounts only about $63 \%$ with higher content of eugenol and benzyl benzoate. In contrast, eugenol was the major component in leaf oil of cinnamon, which accounts for about $80 \%$ and $87 \%$ in Sri Gamunu and Sri Vijaya, respectively. The study revealed that the best maturity stage to harvest both varieties of cinnamon is 2-2.5 years of maturity for maximum quality and quantity of cinnamon bark oil.
\end{abstract}

Keywords: cinnamon, cinnamon bark oil, cinnamon leaf oil, cinnamon maturity

\section{Introduction}

Cinnamon (Cinnamomum zeylanicum Blume; syn: C. verum Presl) is an indigenous spice crop endemic to Sri Lanka. Cinnamon and Cassia are the only commercially distributed and the oldest known species of genus Cinnamomum Schaeffer of family Lauraceae. Ceylon Cinnamon (C. zeylanicum) has been originated in the hill 
country of Sri Lanka and later it has been cultivated in low country areas, especially in the south-west coastal belt, spreading out to five major cinnamon growing districts, namely Galle, Matara, Hambantota, Kalutara, and Rathnapura. C. zeylanicum, which is also popular as the 'True Cinnamon' is exported to many countries including the USA, Mexico, and Europe exceeding Rs. 19000 million export revenue per year and it accounts for 90 percent of world consumption of True Cinnamon (Central Bank Annual Report 2017).

Even though the chemical constituents and quantities of $C$. zeylanicum have been studied by several researchers into a certain extent in the last four decades, they are limited to isolated sample collection without considering agro-ecological and physiological dependences. Wijesekara et al. (1974) reported the chemical constituents of volatile oils extracted from leaves, stem-bark and root-bark of samples collected from two estates in Ambalangoda, Sri Lanka. Paranagama et al. (2001) reported a comparison of essential oil constituents of fruits with those of oils extracted from leaves, stem-bark and root-bark in cinnamon samples collected at a site in Hikkaduwa which lies in the same agro-ecological zone as Ambalangoda. Recently two groups have reported a comparison of chemical constituents in volatile oils of True Cinnamon and wild varieties. In these comparisons, Liyanage et al. (2017) compared the major chemical constituents in the volatile oils of True Cinnamon with those in volatile oils of five wild cinnamon species, while Ariyarathna et al. (2018) compared the morphological and chemical characteristics of two accessions, Sri Gamunu, and Sri Vijaya, with those of six wild cinnamon species. Apart from these limited studies on Ceylon Cinnamon for the samples collected from real cinnamon cultivations within Sri Lanka, there are a number of studies reported for the samples collected as dried materials from the markets and plant samples from cultivated estates outside Sri Lanka (Senanayake et al. 1978, Jayaprakasha et al. 1997). On the other hand, the variation in oil quality, quantity and chemical constituents in relation to the maturity stage of Ceylon Cinnamon harvesting has not yet been reported.

In a study of variation of a parameter at a specific condition, it is essential to keep all the other external factors (variables), which may also affect the parameter as invariants. Propagation of cinnamon is usually carried out by seed propagation which causes the cross-pollination due to protogynous and dichogamy and hence a genetic variation may occur from plant to plant (Azad et al. 2015). On the other hand, vegetative propagation, that carries the same genetic materials from parent plants to progenies, ensures the uniformly high yielding populations and propagating elite lines (Rema et al. 1997). Morphological diversity and agro-ecological variation are also factors that affect the quality and the quantity of the chemical constituents of cinnamon. In this study, the maturity dependence of oil quality and quantity was characterized in two accessions of Ceylon Cinnamon, Sri Gamunu and Sri Vijaya, vegetatively cultivated (Wijesinghe and Gunarathna 2003, Wijesinghe et al. 2004) at the same agro-ecological zone maintaining both genetic factor and ecological factor as invariants. Extensive literature survey and our experience in the progress of cinnamon research ensure that no systematic work on the maturity dependence has been carried out and published elsewhere. 


\section{Material and Methods}

During this study, the accepted standard analytical techniques and the procedures were used for all the steps. Major steps from the site selections to the final data analysis are the sample collections and the preparations, the sample analysis, and the statistical data treatments.

The samples from two vegetatively propagated cinnamon varieties, Sri Gamunu (G) and Sri Vijaya (V), at three different maturity stages (M1: more than 5 years, M2: 22.5 years and M3: 1.5-2 years) have been treated as below. The results have been analyzed as two-factor factorials design. The first factor is the variety with two levels (Gamunu \& Vijaya) and the second factor is the maturity with three levels.

\subsection{Sample collections and preparations}

The study was conducted at the National Cinnamon Research and Training Center, Palolpitiya, Matara, Sri Lanka $\left(6^{0} 1.7820^{\prime} \mathrm{N} ; 8^{0} 33.4990^{\prime} \mathrm{E} ; 22.3\right.$ amsl.) and also where all the samples were collected maintaining the same ecological zone, IL1a. Twenty four cinnamon sticks at three different maturity stages were harvested from Sri Gamunu and Sri Vijaya varieties. Morphological parameters such as length, girth at breast height, and weight of each stick were recorded. The fresh and dry weights of leaves per stick were measured and recorded, and for the bark samples, same parameters were measured after the peeling.

\subsection{Analytical methods}

Four replicate samples from each maturity stage summing up to a total of 24 cinnamon bark samples and 24 leaf samples were analyzed to represent three maturity levels from two varieties: Sri Gamunu and Sri Vijaya. The samples were then tested for the oil content preceded by the extraction, and for the chemical compositions.

\section{Determination of bark and leaf oil quantity}

The modified Clevenger method and water distillation were used (AOAC International, 962.17 - Volatile Oil in Spice) in the determination of the bark and the leaf oil quantity (AOAC, 1995). A 50-100g of each sample was broken into small pieces and placed into a cleaned $1000 \mathrm{~mL}$ distillation flask and followed by adding 500 $\mathrm{ml}$ of deionized water into the flask. The flask was then connected to the Clevenger's arm and the graduated tube of the Clevenger was filled with deionized water up to 5 $\mathrm{mL}$ level and followed by $3 \mathrm{~mL}$ of analytical grade hexane and ether mixture. Then the distillation flask was placed on the heating unit powered by electricity. After the remaining Clevenger arm was connected to the Liebig condenser, the sample was subjected to the distillation for about 4 hours. The hexane and ether mixture containing oil was separated from water and collected into a clean, oven dried and pre-weighted bottle. The bottles were kept open for about 24 hours to evaporate the hexane and ether. 
Then, minute water particles suspended in oil were removed by using a glass syringe and extracted moisture-free oil was weighed. The volatile oil content of each sample was calculated by the equation,

$$
\text { Volatile oil } \%=\frac{\text { weight of oil }(g)}{\text { dry matter content of the sample }} \times 100
$$

\section{Determination of chemical compositions}

The GCMS analyses of the oils were carried out using a Trace 1300/ISQ QD Gas Chromatography Mass Spectrometer equipped with a TG-WAXMS column (30 m long $\times 0.25 \mathrm{~mm}$ inner diameter; $0.25 \mu \mathrm{m}$ film thickness). The transfer line and ion source temperatures were maintained at $220{ }^{\circ} \mathrm{C}$ and $200{ }^{\circ} \mathrm{C}$, respectively. The oven temperatures were programmed linearly from $60^{\circ} \mathrm{C}$ to $210^{\circ} \mathrm{C}$ in the rate of $3^{\circ} \mathrm{C} \mathrm{min}^{-1}$. Mass spectra were acquired in EI mode $(70 \mathrm{eV})$ in the mass range of 50 to 500 (amu). Helium was used as the carrier gas. A $50 \mu \mathrm{L}$ aliquot of essential oil was diluted to 1 $\mathrm{mL}$ with methanol and then the aliquot $(0.5 \mu \mathrm{L})$ of the diluted essential oil solution was injected into the Gas Chromatography Mass Spectrometer.

Identification of the individual component in the oil was accomplished by the comparison of retention time with standard substances and by matching mass spectral data with the MS library (NIST MS search 2.0) using a computer search.

\subsection{Data analysis}

Data obtained on morphological variation, oil content, chemical constituents (cinnamaldehyde, cinnamyl acetate, eugenol, linalool and benzyl benzoate) were subjected to the analysis of variance (ANOVA) under two factor (variety and maturity) factorial design to find the statistical significance and means separation. Data processing was conducted by the SAS version 9.1 computer software package.

\section{Results}

Recorded morphological parameters, oil contents and oil quality of bark and leaf of two cinnamon varieties at three different maturity stages were given in this section. The mean values in each column of data tables superscripted by the same letter are not significantly different at the significance level $\alpha=0.05$ ( $P>0.05$ ), and where mean values are significant, the $\mathrm{p}$-level is given on the last row of each factor.

\subsection{The morphological comparison}

Analysis of growth parameters is important to determine the best harvesting time for maximum economic benefits. The mean values of the length and the girth of stems, fresh stick weight, bark dry weight and leaf dry weight at three different maturity stages 
of Sri Gamunu variety are graphically compared in the Figure 1. Table 1 gives the statistical comparisons of morphological parameters in the growth of two varieties at three different maturity stages.

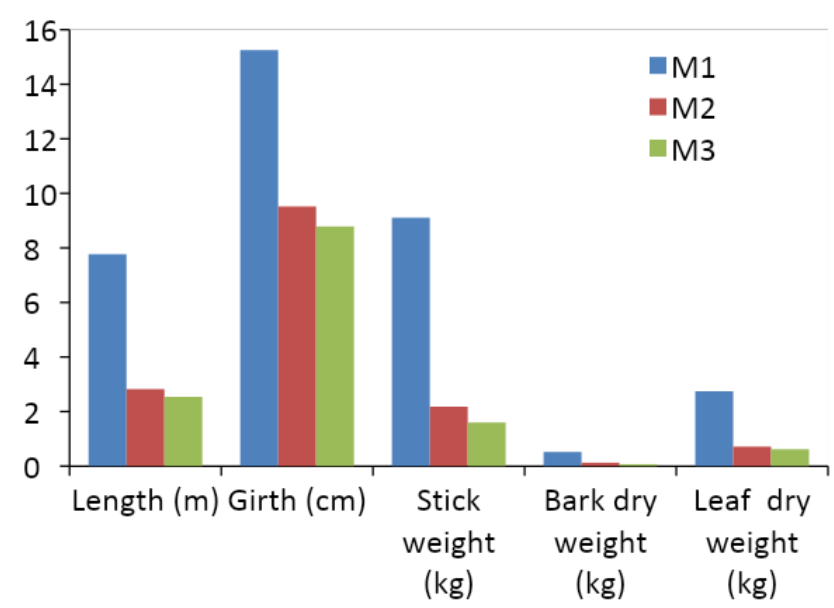

Fig. 1: Comparison in mean values of morphological parameters between three maturity stages (M1, M2 and M3) of Sri Gamunu cinnamon variety.

Table 1: Mean values of growth parameters of cinnamon at different maturity levels $(n=4)$ (values in each column for a given factor superscripted by the shared letter are not significantly different $(\mathrm{P}>0.05))$.

\begin{tabular}{|c|c|c|c|c|c|c|}
\hline Factor & Levels & $\begin{array}{l}\text { Length } \\
(\mathrm{cm})\end{array}$ & $\begin{array}{l}\text { Girth } \\
(\mathrm{cm})\end{array}$ & $\begin{array}{l}\text { Stick } \\
\text { weight } \\
\text { (kg) }\end{array}$ & $\begin{array}{l}\text { Bark dry } \\
\text { weight } \\
\text { (kg) }\end{array}$ & $\begin{array}{l}\text { Leaf dry } \\
\text { weight } \\
\text { (kg) }\end{array}$ \\
\hline \multirow[t]{3}{*}{ Variety } & Gamunu (G) & $366.67^{\mathrm{a}}$ & $11.81^{\mathrm{a}}$ & 3.871 & 0.264 & 1.267 \\
\hline & Vijaya (V) & $508.42^{\mathrm{b}}$ & $10.57^{b}$ & 4.722 & 0.212 & 1.455 \\
\hline & Significance & $* *$ & $*$ & NS & NS & NS \\
\hline \multirow[t]{4}{*}{ Maturity } & M1 & $776.50^{\mathrm{a}}$ & $15.25^{\mathrm{a}}$ & $9.112^{\mathrm{a}}$ & $0.518^{\mathrm{a}}$ & $2.749^{\mathrm{a}}$ \\
\hline & M2 & $281.75^{b}$ & $9.52^{\mathrm{b}}$ & $2.177^{b}$ & $0.125^{b}$ & $0.715^{b}$ \\
\hline & M3 & $254.37^{\mathrm{b}}$ & $8.79^{b}$ & $1.600^{\mathrm{b}}$ & $0.070^{\mathrm{b}}$ & $0.618^{b}$ \\
\hline & Significance & $* * *$ & $* * *$ & $* * *$ & $* * *$ & $* * *$ \\
\hline \multirow{7}{*}{$\begin{array}{l}\text { Variety x } \\
\text { Maturity }\end{array}$} & G x M1 & $482.00^{b}$ & 15.25 & $6.695^{b}$ & 0.525 & 2.329 \\
\hline & Gx $\mathrm{M} 2$ & $363.75^{\text {bd }}$ & 10.50 & $3.059^{\mathrm{c}}$ & 0.187 & 1.054 \\
\hline & G x M3 & $254.25^{\mathrm{cd}}$ & 9.67 & $1.860^{\mathrm{c}}$ & 0.079 & 0.417 \\
\hline & V x M1 & $1071.00^{\mathrm{a}}$ & 15.25 & $11.530^{\mathrm{a}}$ & 0.512 & 3.170 \\
\hline & V x M2 & $199.75^{\mathrm{cd}}$ & 8.55 & $1.295^{\mathrm{c}}$ & 0.062 & 0.375 \\
\hline & $\mathrm{V} \times \mathrm{M} 3$ & $254.50^{\mathrm{cd}}$ & 7.90 & $1.341^{\mathrm{c}}$ & 0.061 & 0.820 \\
\hline & Significance & $* * *$ & NS & $* * *$ & NS & NS \\
\hline
\end{tabular}

Significant levels are given $\alpha$ as $*=0.05, * *=0.01$ and ${ }^{* * *}=0.001$. NS indicates no significance. 


\subsection{The oil content comparison}

The oil content of each cinnamon variety at three different maturity stages was investigated. The mean percentage values of oil contents in the bark and the leaf for two varieties at three maturity stages are graphically presented in the Figure 2, while statistical analysis of those are given in the Table 2.

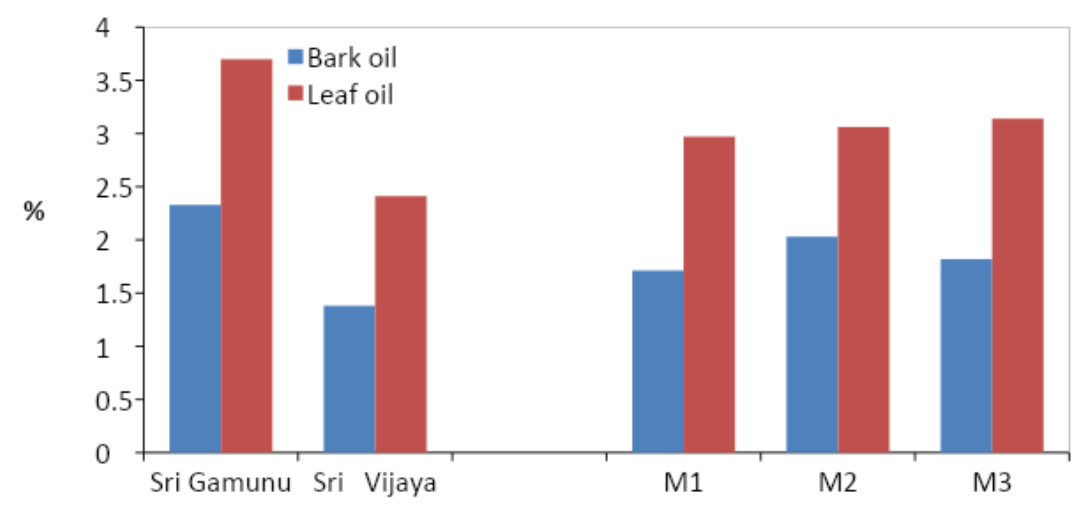

Fig. 2: The comparisons of the oil contents in the bark and the leaf of Sri Gamunu and Sri Vijaya at three different maturity stages (M1: maturity over five years, M2: maturity between 2.0-2.5 years, M3: maturity between $1.5-2.0$ years)

Table 2: Mean percentage values of oil contents in the bark oil and the leaf oil of Sri Gamunu and Sri Vijaya at different maturity levels for four replicates $(n=4)$ (values in each column for a given factor superscripted by the shared letter are not significantly different $(P>0.05))$.

\begin{tabular}{llll}
\hline Factor & Levels & Bark oil content & Leaf oil content \\
& & & \\
\hline Variety & Gamunu (G) & $2.33^{\mathrm{a}}$ & $3.70^{\mathrm{a}}$ \\
& Vijaya (V) & $1.38^{\mathrm{b}}$ & $2.41^{\mathrm{b}}$ \\
& Significance & $* * *$ & $* * *$ \\
Maturity & M1 & $1.71^{\mathrm{b}}$ & 2.97 \\
& $\mathrm{M} 2$ & $2.03^{\mathrm{a}}$ & 3.06 \\
& $\mathrm{M} 3$ & $1.82^{\mathrm{b}}$ & 3.14 \\
Variety $\mathrm{x}$ & Significance & $* *$ & $\mathrm{NS}$ \\
Maturity & G x M1 & 2.12 & $3.90^{\mathrm{a}}$ \\
& G x M2 & 2.53 & $3.30^{\mathrm{b}}$ \\
& G x M3 & 2.32 & $3.90^{\mathrm{a}}$ \\
& V x M1 & 1.29 & $2.04^{\mathrm{c}}$ \\
& V x M2 & 1.53 & $2.81^{\mathrm{d}}$ \\
& V x M3 & 1.33 & $2.38^{\mathrm{a}}$ \\
& Significance & NS & $* * *$ \\
\hline
\end{tabular}

Significant levels are given $\alpha$ as $*=0.05, * *=0.01$ and $* * *=0.001$. NS indicates no significance. 


\subsection{The comparison of chemical constituents in bark oil}

The analysis of maturity dependences was studied further by the level of the chemical components present in the oil. As in previous steps, we analyzed the chemical constituents in the bark oils considering both variety factor and maturity factor (Table 3 ). The variations of chemical constituents (quality) of the bark oil (in the average of Sri Gamunu and Sri Vijaya) with the maturity are shown in the Figure 3.

Table 3: Mean percentage values of different chemical compounds in the bark oil of Sri Gamunu and Sri Vijaya at different maturity levels for four replicates $(n=4)$ (values in each column for a given factor superscripted by the shared letter are not significantly different $(\mathrm{P}>$ $0.05)$ ).

\begin{tabular}{|c|c|c|c|c|c|c|}
\hline Factor & Levels & $\begin{array}{l}\text { alpha } \\
\text { linalool }\end{array}$ & $\begin{array}{l}\text { cinnamal- } \\
\text { dehyde }\end{array}$ & $\begin{array}{l}\text { cinnamyl } \\
\text { acetate }\end{array}$ & eugenol & $\begin{array}{l}\text { benzyl } \\
\text { benzoate }\end{array}$ \\
\hline \multirow[t]{4}{*}{ Variety } & Gamunu (G) & $4.61^{\mathrm{a}}$ & $65.50^{\mathrm{a}}$ & $12.93^{\mathrm{b}}$ & $2.25^{\mathrm{b}}$ & $0.82^{b}$ \\
\hline & Vijaya (V) & $2.86^{\mathrm{b}}$ & $34.85^{\mathrm{b}}$ & $29.00^{\mathrm{a}}$ & $11.53^{\mathrm{a}}$ & $9.07^{\mathrm{a}}$ \\
\hline & Significance & $* * *$ & $* * *$ & $* * *$ & $* * *$ & $* * *$ \\
\hline & M1 & $4.18^{\mathrm{a}}$ & $52.78^{\mathrm{a}}$ & $15.094^{\mathrm{c}}$ & $9.92^{\mathrm{a}}$ & 5.23 \\
\hline \multirow[t]{4}{*}{ Maturity } & M2 & $3.25^{\mathrm{b}}$ & $51.83^{\mathrm{a}}$ & $21.469^{\mathrm{b}}$ & $5.27^{\mathrm{b}}$ & 5.64 \\
\hline & M3 & $3.76^{\mathrm{ab}}$ & $45.99^{b}$ & $26.323^{\text {a }}$ & $5.49^{\mathrm{b}}$ & 5.97 \\
\hline & Significance & $* * *$ & $* * *$ & $* * *$ & $* * *$ & NS \\
\hline & G x M1 & $5.56^{\mathrm{a}}$ & $64.62^{a b}$ & $12.69^{\mathrm{cd}}$ & $3.05^{\mathrm{c}}$ & $0.80^{\mathrm{c}}$ \\
\hline Variety & G xM2 & $3.58^{\mathrm{c}}$ & $68.95^{\mathrm{a}}$ & $11.13^{\mathrm{d}}$ & $1.38^{\mathrm{d}}$ & $0.91^{\mathrm{c}}$ \\
\hline $\mathrm{x}$ & G xM3 & $4.68^{\mathrm{b}}$ & $62.93^{b}$ & $14.96^{\mathrm{cd}}$ & $2.33^{\mathrm{cd}}$ & $0.76^{c}$ \\
\hline \multirow[t]{4}{*}{ Maturity } & V xM1 & $2.82^{\mathrm{c}}$ & $40.93^{c}$ & $17.50^{c}$ & $16.79^{\mathrm{a}}$ & $9.67^{\mathrm{a}}$ \\
\hline & V xM2 & $2.91^{\mathrm{c}}$ & $34.70^{\mathrm{b}}$ & $31.81^{\mathrm{b}}$ & $9.16^{\mathrm{b}}$ & $10.38^{\mathrm{a}}$ \\
\hline & V xM3 & $2.84^{\mathrm{c}}$ & $28.92^{c}$ & $37.68^{\mathrm{a}}$ & $8.64^{b}$ & $7.18^{b}$ \\
\hline & Significance & $* * *$ & $* *$ & $* * *$ & $* * *$ & $* * *$ \\
\hline
\end{tabular}

Significant levels are given $\alpha$ as $*=0.05, * *=0.01$ and $* * *=0.001$. NS indicates no significance.

\subsection{The comparison of chemical constituents in leaf oil}

The variations of chemical constituents in the leaf oil with the maturity are shown in the Figure 4, while their statistical comparisons are given in Table 4 with the variation of the quantity of those chemical constituents with the genotype taken as the average of three maturity stages. 


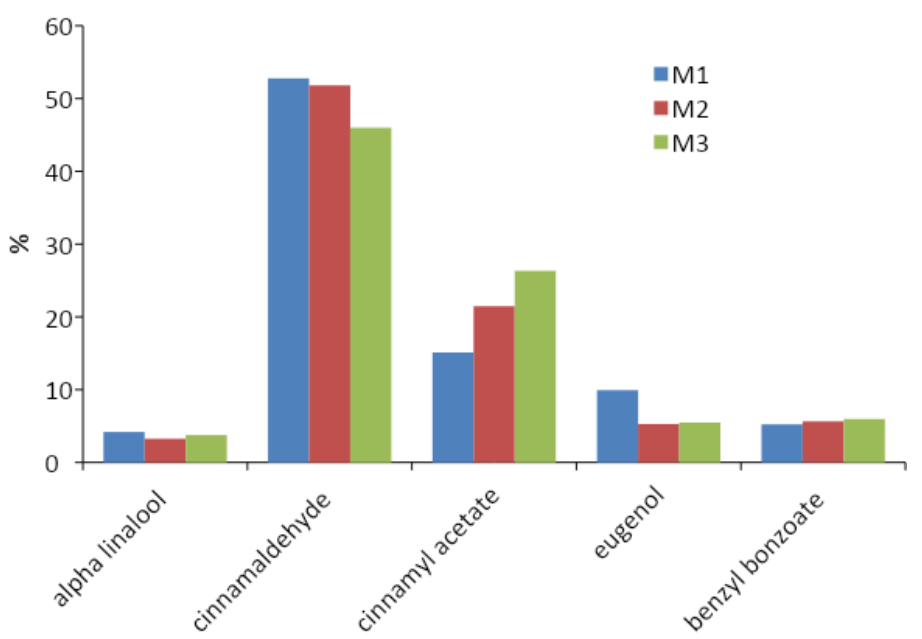

Fig. 3: The comparisons of chemical constituents in the bark oil of Sri Gamunu and Sri Vijaya in average at three different maturity stages (M1: maturity over five years, M2: maturity between 2.0-2.5 years, M3: maturity between 1.5 -2.0 years).

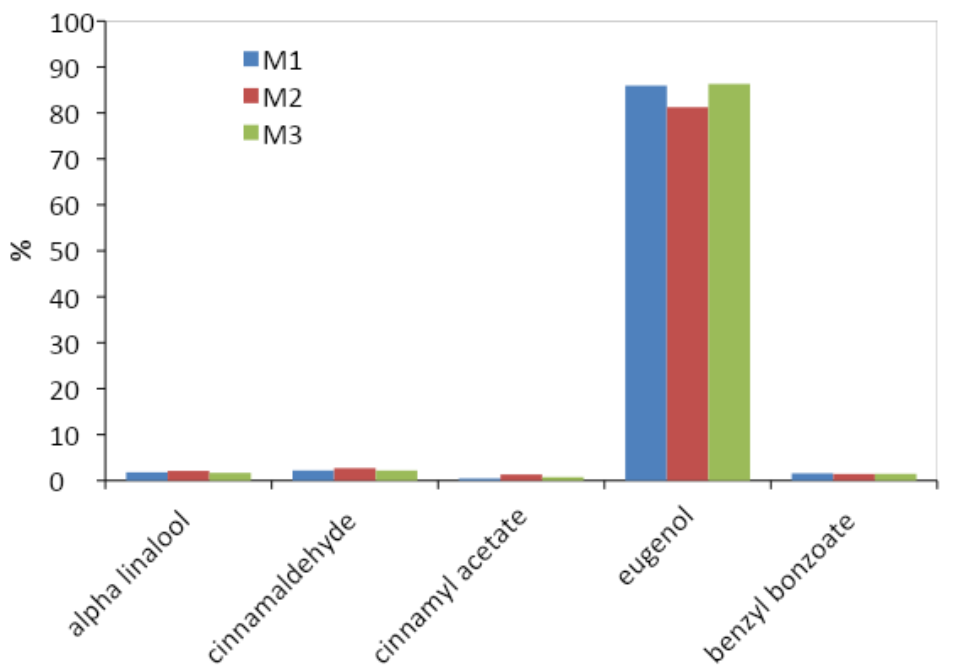

Fig. 4: The comparisons of chemical constituents in the leaf oil of cinnamon at three different maturity stages (M1: maturity over five years, M2: maturity between 2.0-2.5 years, M3: maturity between $1.5-2.0$ years) 
Table 4: Mean percentage values of different chemical compounds in the leaf oil of Sri Gamunu and Sri Vijaya at different maturity levels for four replicates $(n=4)$ (values in each column for a given factor superscripted by the shared letter are not significantly different $(\mathrm{P}>0.05))$.

\begin{tabular}{|c|c|c|c|c|c|c|}
\hline Factor & Levels & $\begin{array}{l}\text { alpha } \\
\text { linalool }\end{array}$ & $\begin{array}{l}\text { cinnamal- } \\
\text { dehyde }\end{array}$ & $\begin{array}{l}\text { cinnamy } \\
1 \text { Acetate }\end{array}$ & eugenol & $\begin{array}{l}\text { benzyl } \\
\text { benzoate }\end{array}$ \\
\hline \multirow[t]{3}{*}{ Variety } & Gamunu (G) & 1.92 & 2.46 & 0.73 & $81.60 \mathrm{~b}$ & $2.57 \mathrm{a}$ \\
\hline & Vijaya (V) & 1.81 & 2.27 & 0.96 & $87.40 \mathrm{a}$ & $0.47 \mathrm{~b}$ \\
\hline & Significance & NS & NS & NS & $* * *$ & $* * *$ \\
\hline \multirow[t]{4}{*}{ Maturity } & M1 & 1.81 & $2.20 \mathrm{~b}$ & $0.46 \mathrm{~b}$ & $85.91 \mathrm{a}$ & 1.58 \\
\hline & M2 & 2.11 & $2.71 \mathrm{a}$ & $1.33 \mathrm{a}$ & $81.27 \mathrm{~b}$ & 1.44 \\
\hline & M3 & 1.68 & $2.19 \mathrm{~b}$ & $0.75 \mathrm{ab}$ & $86.32 \mathrm{a}$ & 1.47 \\
\hline & Significance & NS & $*$ & $*$ & $* * *$ & NS \\
\hline Variety $\mathrm{x}$ & G x M1 & 1.93 & $2.05 \mathrm{bc}$ & 0.28 & $81.92 \mathrm{~b}$ & $2.90 \mathrm{a}$ \\
\hline \multirow[t]{6}{*}{ Maturity } & $\mathrm{G} \times \mathrm{M} 2$ & 1.98 & $2.80 \mathrm{a}$ & 1.42 & $79.43 \mathrm{~b}$ & $2.05 \mathrm{a}$ \\
\hline & $\mathrm{G} \times \mathrm{M} 3$ & 1.88 & $2.52 \mathrm{ab}$ & 0.50 & $83.46 \mathrm{~b}$ & $2.76 \mathrm{a}$ \\
\hline & V x M1 & 1.70 & $2.34 \mathrm{abc}$ & 0.64 & $89.90 \mathrm{a}$ & $0.27 \mathrm{~b}$ \\
\hline & $\mathrm{V} \times \mathrm{M} 2$ & 2.24 & $2.62 \mathrm{ab}$ & 1.25 & $83.12 \mathrm{~b}$ & $0.82 \mathrm{~b}$ \\
\hline & V x M3 & 1.48 & $1.86 \mathrm{c}$ & 1.00 & $89.19 \mathrm{a}$ & $0.17 \mathrm{~b}$ \\
\hline & Significance & NS & $*$ & NS & $* * *$ & $* * *$ \\
\hline
\end{tabular}

Significant levels are given $\alpha$ as $*=0.05, * *=0.01$ and $* * *=0.001$. NS indicates no significance.

\section{Discussion}

The length and the girth of stems show a significant difference in two varieties. Stem length in Sri Vijaya variety is significantly higher $(\mathrm{P}<0.01)$ than that of Sri Gamunu while the stem girth shows the opposite. Stick weight, bark dry weight, and leaf dry weight per stick are not significantly different between two varieties. With the increase of maturity (harvesting time period from maturity level 3 to level 1), the length and the girth of the stem, stem weight, bark dry weight, and leaf dry weight per stick increased showing very high significant difference $(\mathrm{P}<0.001)$. Interaction between variety and maturity is statistically deferent for the length of the stem and the weight per stick while the girth of the stem, the bark dry weight, and the leaf dry weight per stick are not significantly different. These results revealed that the cinnamon variety (either Sri Gamunu or Sri Vijaya) is not a considerable factor for the quantity of the raw product of the cinnamon such as bark dry weight and leaf dry weight. The maturity factor is significant but further analysis of its effect on oil quality and quantity will be discussed on following subsequent sections.

Bark oil and leaf oil contents of two varieties show a significant difference at three maturity stages. The oil percentages in the leaf and the bark are significantly higher in Gamunu variety than Vijaya variety despite the fact that there is no significant difference in dry weight as discussed above. This is in accordance with the report 
presented by Indrasena et al. (2010) that the highest oil content (3.06\%) was observed in Sri Gamunu.

Significantly the highest bark oil content can be observed in the maturity stage two (M2) of cinnamon, which is a somewhat over matured stage (about 2-2.5 years), compared to the normal harvesting maturity (maturity stage M3) and the over matured cinnamon (maturity stage M1). There is no significant difference in leaf oil content among three maturity stages. Although there is no significant interaction between variety factor and maturity factor for the bark oil content, there is a significant interaction between variety and maturity in the leaf oil content.

All the components of the bark oil taken as the average of three maturity stages are significantly different between the two varieties (Table 3). The percentage of alpha linalool and cinnamaldehyde are higher in Sri Gamunu (G) over Sri Vijaya (V) while cinnamyl acetate (acetic cinnamyl ester), eugenol and benzyl benzoate show opposite relation. All the tested components show significant differences among three maturity stages. Cinnamaldehyde, eugenol and alpha linalool percentages increase significantly with maturity from M3 to M1 even though insignificant deviation could be observed in the case of eugenol at M2. On the other hand, the percentages of cinnamyl acetate and benzyl benzoate decrease with the maturity showing the highest at the immature stage (M3). Noticeable observation is the variation in the major components of cinnamon; the sum of cinnamaldehyde and cinnamyl accounts about to $70 \%$. In comparison, the sum of these two components in maturity stages, M1, M2 and M3 account $69 \%, 73 \%$, and $72 \%$, respectively. Since the maturity stage M1 is over 5 years and M2 is about 2.0-2.5 years of harvesting period, in comparison by both oil quality and harvesting period, harvesting at maturity stage M2 is more economical. When compared with the maturity stage M3, the sum of major components in M2 has higher percentage and hence with the observation made in above section 3.2 that the maturity stage M2 has higher oil content (quantity), it reveals that the maturity stage M2 is the best harvesting time for the bark oil by both quantity and quality considerations for the better economic benefits.

A significant interaction between variety factor and maturity factor can be observed. The sum of cinnamaldehyde and cinnamyl acetate in Gamunu variety $(\mathrm{G} x \mathrm{M})$ for $\mathrm{M} 1$, M2, M3 are $77 \%, 80 \%$ and $78 \%$, respectively and those in Vijaya variety are $58 \%$, and $66 \%$ and $67 \%$, respectively. The similarity to the effect of maturity factor, cross interactions also show that Gamunu has higher quality with respect to the major components, and maturity stage M2 has the higher oil quality.

In contrast to the bark oil, the major component in leaf oil is different. In the bark oil, the major components are cinnamaldehyde and cinnamyl acetate whose sum is above $70 \%$, but in Sri Vijaya, above $80 \%$ is eugenol. This difference in two sets of oil from the same plant makes them used in different industries. In general, bark oil is being used in the food industry while leaf oil is being used in cosmetic industry (Singh et al. 2007, Nabavi et al. 2015). Similarly, there are several reports on numerous medicinal benefits and use of bark and leaf of Ceylon cinnamon (Ranasinghe et al. 2013). Eugenol content in Sri Vijaya variety is considerably higher than that in Sri Gamunu showing the same trend what we observed in the bark oil composition in 
which eugenol content is higher in Sri Vijaya compared to Sri Gamunu. There is no significant difference in all the other minor components between two varieties. There is no significant difference in eugenol contents between maturity stage M3 and M1 while that in stage M2 is significantly lower. A similar observation can be seen in the interactions between two factors.

\section{Conclusions}

This study shows that the best harvesting stage for high-quality cinnamon with high oil yield is the plants of 2- 2.5 years maturity. In addition, the harvesting at lower maturity is also economically beneficial for farmers. The oil content and compositions depend on the variety and hence it reveals that vegetative propagation can be used to maintain the quality and the compositions of both cinnamon bark and leaf oils. As the major chemical components in the bark oil and in the leaf oil are different, two different oil extracts from bark and leaf of the same plant can be used in different purposes such as food industry and cosmetics.

\section{Acknowledgements}

We thank National Science Foundation, Sri Lanka (NSF) for the funding under the research grant SP/CIN/2016/04 and National Cinnamon Research and Training Center, Sri Lank and their staff for the support given to this project. Comments from two anonymous RJS reviewers are acknowledged.

\section{References}

AOAC International. 1995. Official Methods of Analysis of AOAC International, sixteenth ed. Arlington, Virginia.

Ariyarathna HBMA, Weerasuriya SN, Senerath WTPSK. 2018. Comparison of morphological and chemical characteristics of two selected accessions and six wild species of genus Cinnamomum Schaeff. Sri Lankan Journal of Biology 3, 11-23.

Azad R, Senanayake G, Wasantha Kumara KL, Ranawaka RAAK, Pushpakumara DKNG, Wijesinghe KGG, Geekiyanage S. 2015. Morphological variation within progeny and deviations from mother plant reveal the allele richness in Cinnamomum verum germ-plasm: a case study from Deiyandara, Matara collection at the early vegetative stage. Tropical Agricultural Research \& Extension 18, 163-167.

Central Bank Annual Report. 2017. Central Bank of Sri Lanka, 30, Janadhipathi Mawatha, Colombo 01, Sri Lanka, Appendix 17, Table 73.

Indrasena IK, Induruwa IVADCS, Liyanage T, Wijesinghe KGG, Edirisinghe EDK. 2010. Comparative assessment of oil and coumarin content in bark of cassia (Cinnamomum cassia) and true cinnamon (Cinnamomum zeylanicum). Proceedings of International Symposium, University of Ruhuna part I, p. 26.

Jayaprakasha GK, Rao LJ, Sakariah KK. 1997. Chemical composition of volatile oil from Cinnamomum zeylanicum buds. Flavour and Fragrance Journal 12, 331-333.

Liyanage T, Madhujith T, Wijesinghe KGG. 2017. Comparative study on major chemical constituents in volatile oil of True Cinnamon (Cinnamomum verum Presl. syn. C. zeylanicum Blum.) and five wild cinnamon species grown in Sri Lanka. Tropical Agricultural Research 28, 270-280. 
Nabavi SF, Di LorenzoA, Izadi M, Sobarzo-Sánchez E, Daglia M, Nabavi SM. 2015. Antibacterial effects of cinnamon: from farm to food, cosmetic and pharmaceutical industries. Nutrient 7: 7729-7748

Paranagama PA, Wimalasena S. Jayatilake GS, Jayawardene AL, Senanayake UM, Mubarak UM. 2001. A comparison of essential oil constituents of bark, leaf, root and fruit of cinnamon (Cinnamomum zeylanicum Blum) grown in Sri Lanka. Journal of National Science Foundation Sri Lanka 29: 147153.

Ranasinghe P, Pigera S, Premakumara GAS, Galappaththi P, Constantine GR, Katulanda P. 2013. Medicinal properties of 'true' cinnamon (Cinnamomum zeylanicum): a systematic review. BMC Complementary Medicine and Therapies 13: 275.

Rema J, Krishnamoorthy B, Mathew PA. 1997. Vegetative propagation of major tree spices- a review. Journal of Spices and Aromatic Crops 6: 87-105.

Senanayake UM, Lee TH, Will RBH. 1978. Volatile constituents of cinnamon (Cinnamomum zeylanicum) oils. Journal of Agricultural and Food Chemistry 26: 822-824.

Singh G, Maurya S, De Lampasona MP, Catalan CAN. 2007. A comparison of chemical, antioxidant and antimicrobial studies of cinnamon leaf and bark volatile oils, oleoresins and their constituents. Food and Chemical Toxicology 45: 1650-1661.

Wijesekara ROB, Jayawardena AL, Rajapakse LS. 1974. Volatile constituents of leaf, stem and root oils of cinnamon (Cinnamomum zeylanicum). Journal of the Science of Food and Agriculture 25: 12111220 .

Wijesinghe KGG, Gunarathna WDL. 2003. Response of elite cinnamon (Cinnamomum zeylanicum) lines for vegetative propagation. Association for the Advancement of Science, 59 ${ }^{\text {th }}$ Annual Session, proceedings part I, p. 47

Wijesinghe, KGG, Samaraweera, DN, Jayasinghe, D, Gunaratna, GG. 2004. Development of Cinnamon (Cinnamomum verum Presl) selection for higher yields with better quality characteristics. CARP Competitive Contract Research Grants Programme (eds. H.P.M. Gunasena, M.R. Dhanapala \& T.U. Tilekawardana), pp 3-10. Sri Lanka Council for Agricultural Research Policy, Wijerama Mawatha. 